\title{
Mapping of noise impact provoked by the execution of foundation piles at high rise building sites
}

\author{
Adolpho Guido de Araújo a,", Alexandre Duarte Gusmão ${ }^{\mathrm{b}}$, Emilia Rahnemay Kohman Rabbani ${ }^{\mathrm{c}}$ and \\ Stela Paulino Fucale \\ ${ }^{a}$ Civil Engineering Master's Program, Universidade de Pernambuco, Recife, Brasil, adolphoguido@hotmail.com \\ ${ }^{\mathrm{b}}$ Civil Engineering Master's Program, Universidade de Pernambuco, Recife, Brasil, \\ gusmãoalex@yahoo.com.br \\ 'Civil Engineering Master's Program, Universidade de Pernambuco, Recife, Brasil, emilialsht@poli.br \\ dCivil Engineering Master's Program, Universidade de Pernambuco, Recife, Brasil, sfucale@yahoo.com.br
}

\begin{abstract}
The objective of this work is to map, in a limited area inside and outside of the worksite, the environmental impact generated by sound pollution coming from the driving of foundation piles for high rise buildings, as well as to observe and check if the noise levels produced by the emitting source are tolerable in the urban environment. The methodology of the work includes a survey of technical references about the subject; measurement of noises surrounding the worksite during the foundation phase for four distinct buildings, with different types of piles: prefabricated piles, continuous helical displacement piles , traditional compaction piles and Terra Probe compaction piles. A grid of points was built due to the time of driving and after that the measurements of environmental noises were performed emitted by the execution of each type of pile using a sound level meter. The interpretation of the measurements and their impacts on the neighborhood of the building were performed using the computational tool Suffer for creating noise level contours. The $\mathrm{X}$ and $\mathrm{Y}$ axes of the grid represent the distances in meters of the area studied and the $\mathrm{Z}$ axis represents the noise measured in $\mathrm{dB}$. The contours developed represent the mapping of the noise at the worksites and their surroundings. The mapping of the urban impact of noise, the measurement of its dimensions, and the examination of its propagation around the building are important subsides to adequate individual and collective protection procedures. Seventy one points were measured at four building sites with different types of piles, and the results showed that at only three points was the noise within the limits of the Municipal Law of Recife of $70 \mathrm{~dB}$, which proves the relevance of the research. Finally, the comparative analysis between the four types of piles shows that the continuous helical displacement pile emits the lowest noise level among the four pile types studied.
\end{abstract}

Keywords: Sound Pollution, Civil Construction, Foundations, Mapping, Noise

\section{Introduction}

The city of Recife, in recent years, has been suffering the environmental impacts generated by a significant increase in civil construction. Recife has been popularly called the "Construction Site of Northeast."

According to Priori (2008), while Brazil registered a medium annual growth rate of $2.54 \%$, Pernambuco grew $3 \%$, also surpassing the Northeast rate of
$2,42 \%$. In this scenario, civil construction could increase above the average of the State of Pernambuco in the coming years and visibly accelerate from the year 2011 on.

The volume and number of public investments announced, some completed and several predicted in the governmental Growth Acceleration Plan (PAC), are considerable and have helped to establish the image of Pernambuco as an ideal state for productive

*Corresponding authors e-mails: adolphoguido@hotmail.com and emilialsht@poli.br 
investments. This growth improves human development, and heats up the real estate market.

According to direct research carried out by the Federation of Industries of the State of Pernambuco, in the month of September 2009, the sales velocity index for new residential property reached $10.8 \%, 2$ percent higher than the previous month. This growth was largely due to the sales performance of property launched during the month. The annual rate increase was $8.3 \%$, overcoming the mark of $2008(7.9 \%)$.

To observe numerically the habitation growth in Recife, the September survey observed an increase of 1256,9 in launches of new residences compared with the previous month. Corresponding to $54,3 \%$ related to the month of September 2008. The total number of launches in September 2009 was 787 properties, the second best mark recorded for the period, overcoming September 2007, with 669 residences.

Public infrastructure projects, such as the transnortheastern railroad, the four-laning of BR 101, the transposition of the São Francisco River, as well as the production projects like the South Atlantic Yard, the Abreu e Lima Refinery, the polyester and pharmaceutical poles, among others, are large-scale constructions which help to build a strong national and international image and help to carry out the populace's dream of employability.

Economic growth leads to the increase of the income level of the population, increasing the demanding for vertical residential high rise buildings, the socalled "edifícios."

The process of consolidation of the investments of public infrastructure could lead to a substantial increase of demand for housing, which could grow in geometric progression.

Expansion is forecast to be about $8 \%$ annually for the period 2011-2020. This scenario will generate wealth, but also the great responsibility of managing the effects caused by urban density during the of construction phase of the project, with interference in the environment surrounding the site, bringing a high level of disturbance into of the neighborhood.

All this generates a significant concern about the sustainability of traditional construction methods, encouraging research to identify and mitigate these impacts.

Constructions generally cause diverse environmental impacts. Densely urbanized areas suffer these impacts in an aggressive form, disturbing the peace of the neighborhood.

Noise "is a vibrational physical phenomenon with indefinite characteristics pressure vibrations (in the case of air) as a function of frequency, i.e., for a giv- en frequency there can exist variations of pressure randomly over time. [8]."

According to Zannin and Szeremeta [9], noise is common in large urban centers, generated mainly by the means of transportation. The evolution of sound pollution in our environment constitutes a threat to the well being and health of citizens.

All this unpleasant noise disturbs the daily routine and generates more and more complaints to environmental organizations.

This work presents the first results of a research about the environmental impacts as consequence of the execution of several types of foundations. The research was developed by the Master's Program in Civil Engineering (PEC) of the University of Pernambuco (UPE) and involves the impacts of noises and particulate in urban areas.

\subsection{Sound Waves}

The sound phenomena are related with the vibrations of the material objects.

For example: when a person talks, the sound emitted is produced by the vibration of their vocal chords. When a piling machine or heavy equipment vibrates it emits sounds.

All these objects are sound sources that, when they vibrate, they produce waves that propagate in the material environment (solid, liquid or gaseous) located between them and the ear. When they penetrate the ear, these waves provoke sound sensations [4].

According to these authors [4] the sound is a longitudinal wave, which propagates in a material environment, which frequency is comprehended, approximately, between 20 and 20.000 hertz. When this wave is propagated in a material environment with a frequency lower than 20 hertz it is called infra-sound and, if its frequency is above 20.000 hertz, it is called ultra-sound.

\subsection{Environmental impact of the noise in the execution of the foundations}

Environmental impact can be considered as any alteration of the physical, chemical and biological of the environment caused by any form of material or energy resulting of human activities that, directly or indirectly, affect: the health, the security or the well being of the population; the social and economic activities; the biota; the static and sanitary conditions of the environment; and the aesthetic quality of the environmental resources [6]. 
The urban sources considered meaningful come from industries (including civil construction) commerce, vehicles (terrestrial and aerial), leisure, and habitations [1].

In this work some results of measurements of noises caused by the equipment used for making some types of foundations are presented. The measurement of damages caused by these noises around the construction and as well as the labour involved directly and indirectly, with the execution of the foundation.

The equipment used in the evaluation of noises is called sound level meter or, popularly, decibel meter, which is used to measure the level of sound pressure (LSP).

Table 1 presents a summary of the rules related to the noises in urban environment according to the Law \#16243/96 Environment Code of the City of Recife; Technical Norm NBR 10151 of the ABNT; and Conama Resolution \#1 of March, 8th 1990.

Table 1

Law and its threshold noise levels

\begin{tabular}{|c|c|}
\hline Regulation & Threshold limits \\
\hline \multirow{3}{*}{$\begin{array}{l}\text { Law \# 16243/96 } \\
\text { (Environment Code of Recife - } \\
\text { 1996) }\end{array}$} & $\begin{array}{c}55 \mathrm{~dB}(\mathrm{~A})-\text { day } \\
45 \mathrm{db}(\mathrm{A})-\text { night } \\
\text { For school, library and } \\
\text { hospital areas }\end{array}$ \\
\hline & $\begin{array}{l}70 \mathrm{~dB}(\mathrm{~A})-\text { day } \\
60 \mathrm{~dB}(\mathrm{~A})-\text { night }\end{array}$ \\
\hline & $\begin{array}{l}\text { Respected the levels } \\
\text { of the NBR } 10.151 \text { and } \\
\text { NBR } 10.152 \text { of the } \\
\text { ABNT }\end{array}$ \\
\hline NBR 10151 June 2000 & $\begin{array}{l}55 \mathrm{~dB}(\mathrm{~A}) \text { day and } 45 \\
\mathrm{~dB}(\mathrm{~A}) \text { night }\end{array}$ \\
\hline CONAMA \# 1, 1990 & $\begin{array}{c}55 \mathrm{~dB}(\mathrm{~A}) \text { day } \\
45 \mathrm{~dB}(\mathrm{~A}) \text { night }\end{array}$ \\
\hline
\end{tabular}

\section{Methodology}

The research was based on data collection and field measurement to analyze the propagation of noise in the surroundings of four building sites with different types of foundations. During the field research it could be clearly seen that the execution of the foundations generates unpleasant effects to the residential peace of the neighborhood.

The measurements were done using a decibel meter made and calibrated by a company from the United States, attending to the requisites of the Norm IEC61672-1-2002 class 2 measure of meters of sound type 2; ANSI S1.4-1983 (R2001) filter of eighth band class 2; ANSI S1.43-1997 (R2002) for levels of meters of sound type 2 , according to certificate of calibration number: 226105BBI010003.

The measurements were made inside a frame built in two axis ( $\mathrm{X}$ and $\mathrm{Y}$ ) in dimensions that contemplated several points inside the area of the building site (land being built) and in the surroundings of it (outside the land of the construction). The measurements occurred in four different types of foundation.

For elaboration of the contours the computational software "Sufer 8" was used, being two axes X and Y of the grid built in meters for definition and limiting of the planimetry of the area studied and axis $\mathrm{Z}$ represented the noises in each point of the grid in $\mathrm{dB}$ resulting in the noise contours.

With the contours it was possible to map the noise propagation behavior, being the areas in yellow called comfort zone, where the levels of noise respect the maximum limits established by the environment code of the city of Recife.

At the first construction site, concrete prefabricated piles were being executed, with the help of a pestle of free fall with $28 \mathrm{kN}$ weight. In the second construction analyzed continuous helical displacement pile were being executed, with the help of an auger continuous and injection of concrete, under controlled pressure.

In the third construction an improvement of the soil was being done with compaction piles, where a tube is stuck in the soil, sand and gravel is added in proportions determined in the Project, and after several falls of the pestle, the material is compacted. As the material is compacted, the tube is removed from the soil. In the fourth construction an improvement of the soil type pile called Terra Probe was being used, where an equipment called SP-60 is connected to the arm of an hydraulic digger and through vertical vibrations a metallic tube with tilting cover and through a carrier over wheels the material for improvement is introduced in the metallic tube.

\section{Analysis of the results}

\section{Construction 1 - Prefabricated Plies}

Construction 1 is a reinforced concrete frame structure with 18 slabs, located in the neighborhood of Boa Viagem (Fig.1), that was being built by a medium sized construction company.

From the geotechnical characteristics of the land, prefabricated piles of concrete were driven to percus- 
sion with pestle of free fall of $28 \mathrm{kN}$ of weight. The noise provoked by driving the pile E7/Pilar 10, that was constituted by three elements tied every $12 \mathrm{~m}$ each.

Prefabricated piles have the feature of being driven in the terrain by percussion, pressing or vibration and for being part of the group called "displacement piles." They can consist of one unique structural element (wood, steel, reinforced concrete or prestressed) or by the association of two of these elements, which is called a mixed pile.

The prefabricated concrete piles of are produced in reinforced or prestressed form, intensified by centrifugation through vibration or percussion. Figure 1shows the place of the construction of the prefabricated piles drilled by percussion in the surroundings of the area confined by two side buildings and one building in the back.

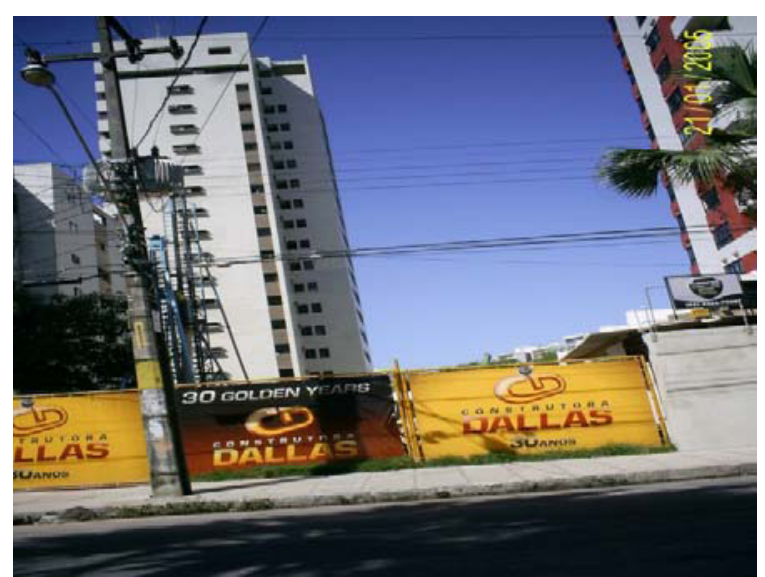

Figure 1 -Surroundings of Construction 1

Figure 2 presents the measurement grid of the construction. Figures 3 and 4 show the spatial distribution and the isolines of noise contours, respectively.

The biggest amplitude of the noise was measured in point 12 (coordinates $7,4 \mathrm{~m}$ and $35,05 \mathrm{~m}$ ) with a value of $95,7 \mathrm{~dB}$. This coordinate is located in the exact point of the source of the noise emission, where the pile drive was.

The smallest amplitude was measured in point 2 $(7,4 \mathrm{~m}$ and $61,05 \mathrm{~m})$ with a value of $78,19 \mathrm{~dB}$. Point 30 is found inside the neighbor building, where a value of $94,9 \mathrm{~dB}$ was registered, measured in a hall of the first floor.

The measurements included 31 points, the points 26 to 31 form the external grid, outside the area built. In all the 31 points monitored the noise is above the limit of tolerance established by the current legislation.
Figure 2 presents the grid of points represented by two orthogonal axes constituted of 31 points. The point in red represents the place of emission of the source of the noise (where the pile was driven).

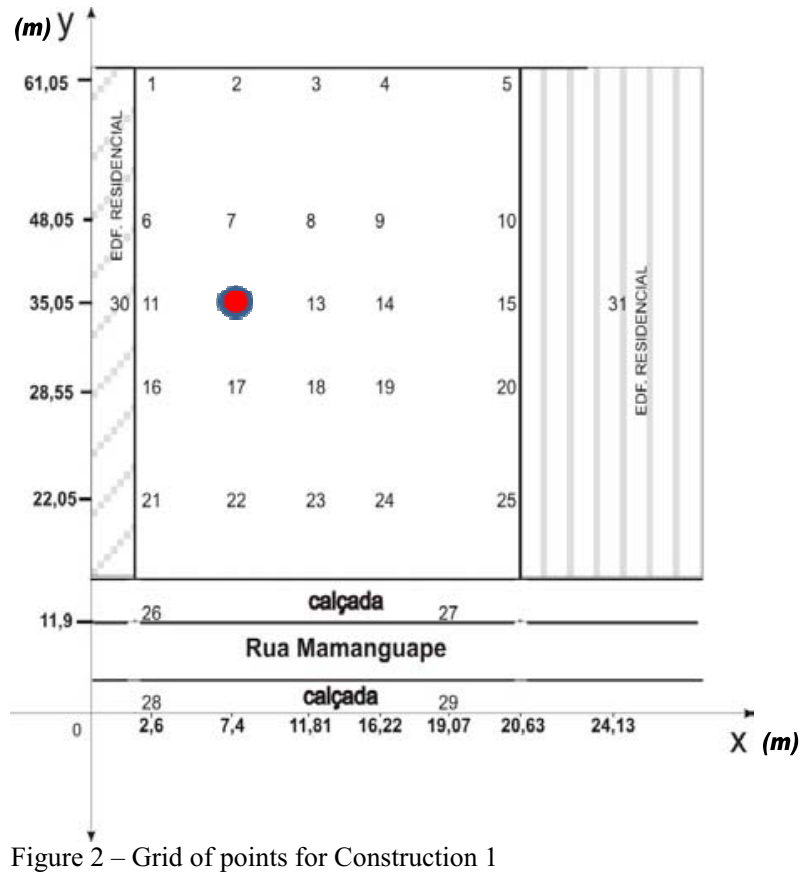

A spatial representation of the noise measured along the built grid was designed and presented in Figure 3, as well as its scale of measure of decibels.
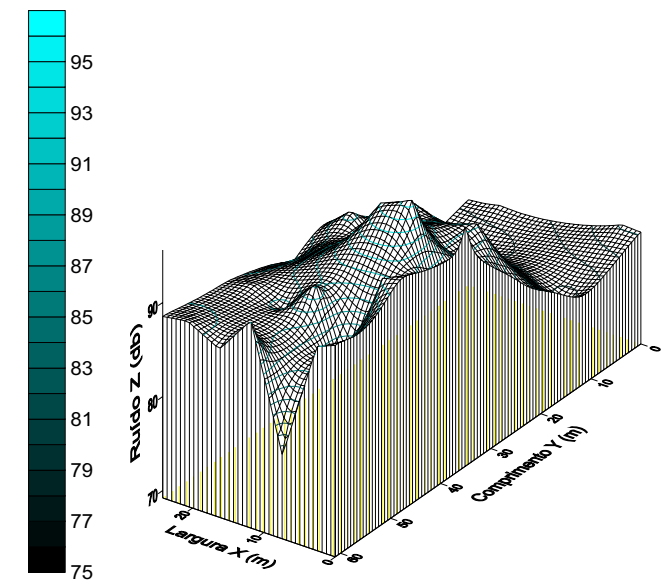

Figure 3 - Spatial noise distribution for Construction 1 


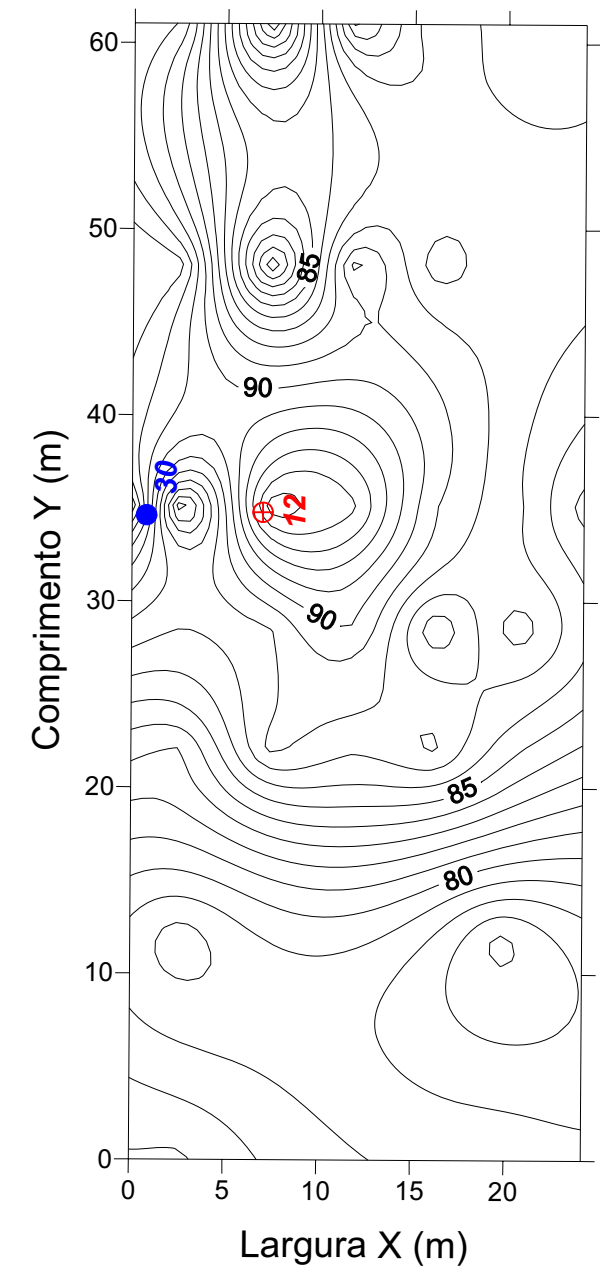

Figure 4 - Isolines of the noise for Construction 1

Construction 2 - Continuous helical displacement pile

These are two constructions with a frame structure of reinforced concrete, located in the neighborhood of Boa Vista (Fig.5) that were being built by a medium sized construction company.

The foundation is the continuous helical displacement pile type that is one of the most modern building methods of deep foundation. This kind of construction was defined due to the geotechnical features of the terrain and planning of viability of the construction. The measurements of noise were made during the execution of the Pile E75/Pilar 05.

The continuous helical displacement pile was a concrete pile molded "is situ", executed through continuous auger and concrete injection, under controlled pressure, through the stem of the auger. While the cement grout was pumped, the auger was slowly withdrawn, lifting the soil on the flights. From the mid 90's, Brazilian market was invaded by machines imported from Europe. The noises emitted normally come from the equipment normally used for executing the helical displacement in the terrain, through the rotation of the same.

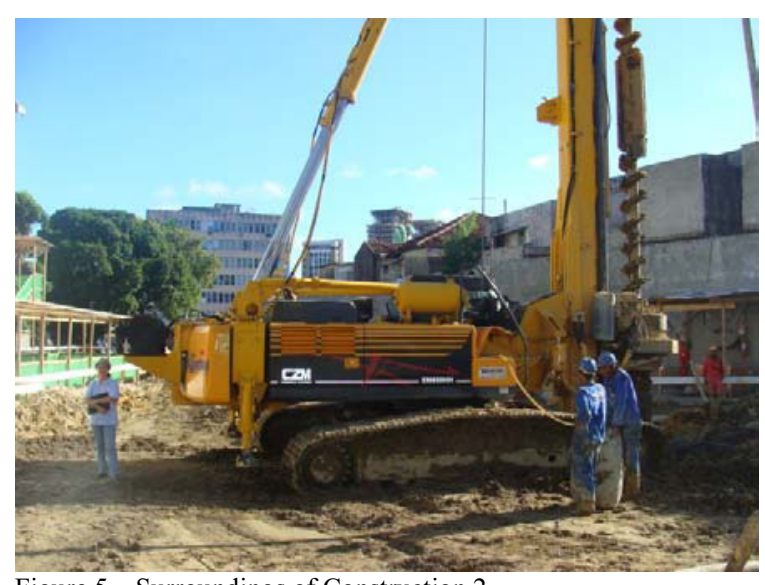

Figure 5 - Surroundings of Construction 2

Figure 6 presents the grid of measurement points of construction 2. Figures 7 and 8 show the spatial distribution and the isolines of the noise, respectively. The biggest noise amplitude was measured in point E75 $(9,4 \mathrm{~m}$ and 26,78$)$ with $85,7 \mathrm{~dB}$, and was located in the point of the noise emission source. The smallest amplitude was measured in point $10(50,5 \mathrm{~m}$ and $35,23 \mathrm{~m}$ ) with a value of $69,4 \mathrm{~dB}$.

The measurements were made in 12 points, points 8 through 12 were outside the construction site. In general the values measured were smaller than the ones measured in the construction site with prefabricated piles, but are still above the threshold limits of the City law.

Figure 6 presents the grid of points represented by two orthogonal axes constituted of twelve points. The red point represents the place of the emission of the noise source. Due to the disorganization of the building site the quantity of points marked inside the area of the construction was smaller. The critical path to go along a bigger area became practically impossible. 


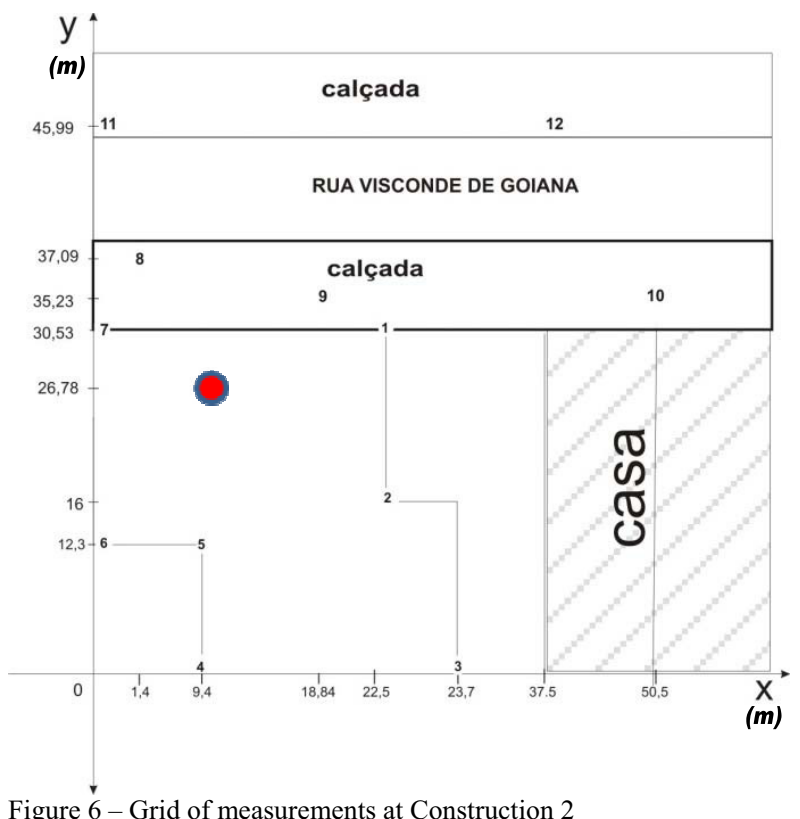

Figure 7 presents the spatial noise distribuition for the grid presented in Figure 6, as well as its scale of measurement in decibels.
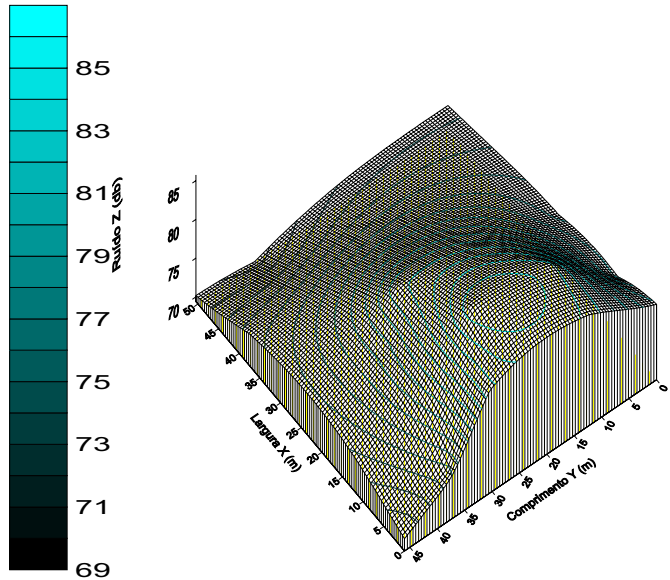

Figure 7- Spatial noise distribution for Construction 2

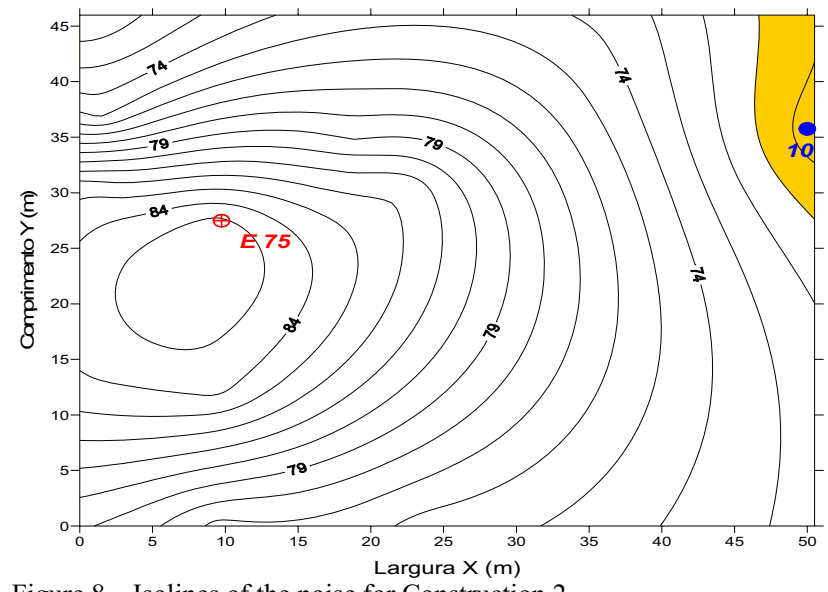

Figure 8 - Isolines of the noise for Construction 2

Construction 3 -Improvement compaction piles

It is an edification with a frame structure of reinforced concrete, located in the neighborhood of Madalena, Recife (Fig.9), being built by a small sized construction company.

Although the building had a shallow foundation was, an improvement of the superficial terrain was done with compaction piles. The measurements of noise were made during the execution of the improvement pile F2/Pilar 10. For execution of the compaction piles, a tube with dried "bucha" was stuck and after that the pile cement grout mix was executed with a pile cap.

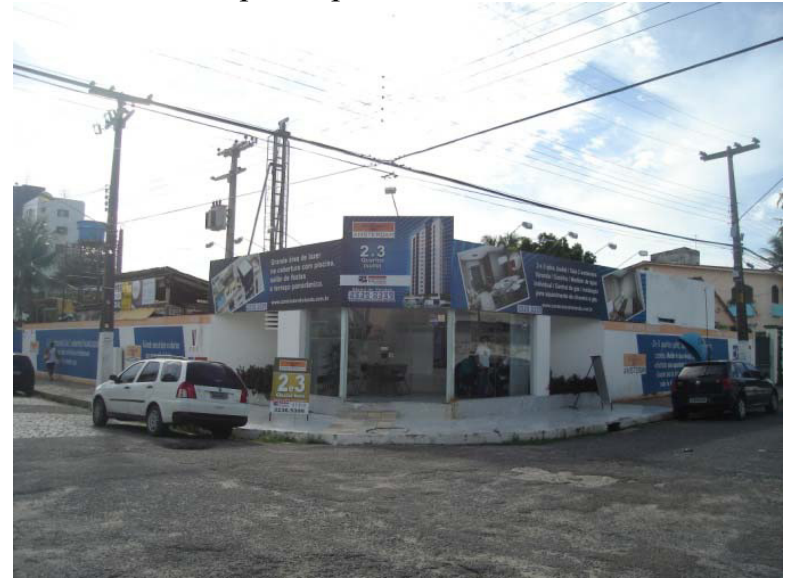

Figure 9 - Surrounding of Construction 3

Figure 10 presents the grid of measurement points collected in construction 3. Figures 11 and 12 show the spatial noise distribution and the noise isolines, respectively. The biggest amplitude of the noise was measured in point $10(0$ and $42,4 \mathrm{~m})$ with a value of $69,2 \mathrm{~dB}$. 
The measurements involved 15 points, the points from 10 to 15 were located outside the construction site. The yellow area presented in Figure 12 is the one that did not pass the threshold noise limits, highlighting that only point 10 had smaller value than 70 $\mathrm{dB}$. In Figure 10 the red point represents the point of the emission of the noise source..

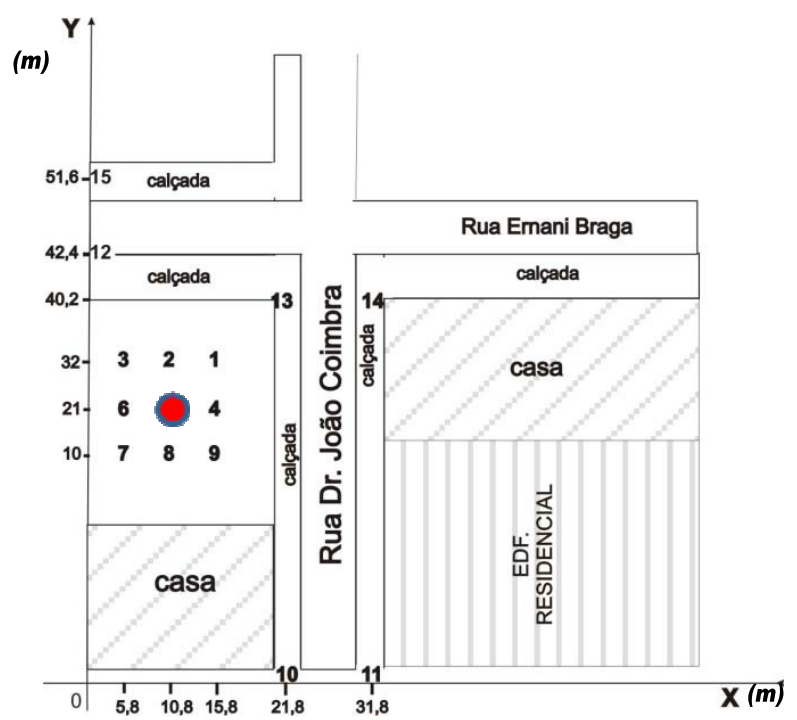

Figure 10 - Grid of measurement points at Construction 3

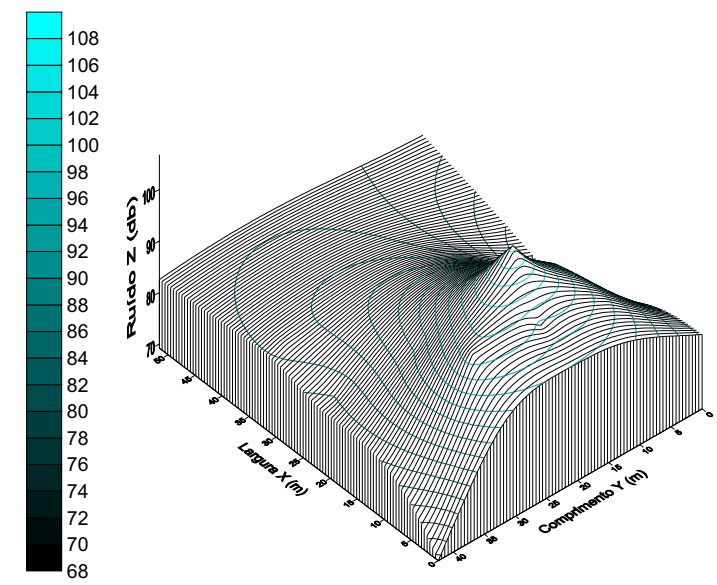

Figure 11 -Spatial Distribution of noise -Construction 3

Figure 12 shows the propagation of noise, having as origin the emitting source. It is observed that the noise tends to the threshold limit when the collection points are about 20 meters distant from the noise source.
The conditions of execution observed are the traditionally performed by foundation companies with total absence of mitigating procedures, such as the use of acoustic barriers and impact absorption.

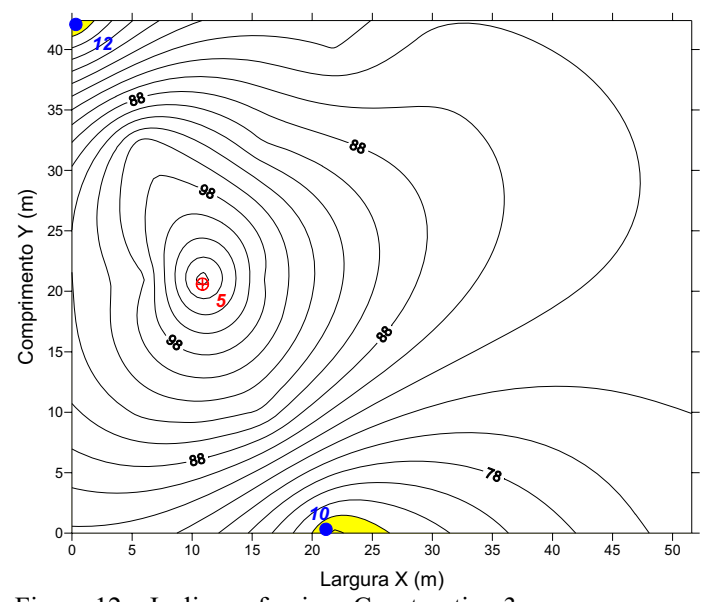

Figure 12 - Isolines of noise -Construction 3

3.1. Construction 4-Compaction piles using vibrating probes -Terra Probe

Construction 4 is a building with a frame structure of reinforced concrete, located in the neighborhood of Torre, Recife (Fig. 13), being built by a small sized construction company.

The foundation is shallow, but the superficial terrain was improved using compaction piles made of a mix of stone powder and gravel after the improvement reinforcement was done in the areas of the pile caps. The noise measurements were made during the day in the period of the afternoon. Twelve measurements were performed, nine inside the terrain and three in the surroundings of the construction on the sidewalk.

For execution of the compaction piles, a tube is drilled with a tilting cover, with a vibrator connected to the arm of the hydraulic mechanic shovel and after that the metallic tube driven in the soil is supplied with improvement material (stone powder and gravel) through a funnel connected to a mechanical shovel. Finally the tube is removed by the vibrator. In the moment in which the metallic tube receives the vertical vibrations for its removal, the material of improvement inside the same is compacted, improving the resistance of the soil.

This method is called Terra Probe and its mechanization can be divided into two parts. The first, heavy equipment, consists of a hydraulic mechanic shovel with an SP-60 connected to its arm, which is responsible for the vibration. The second is the me- 
tallic tube component with a tilting cover. The main purpose of the tilting cover is the same as of the bush of the traditional compaction pile, to block of the entrance of material during pile driving.

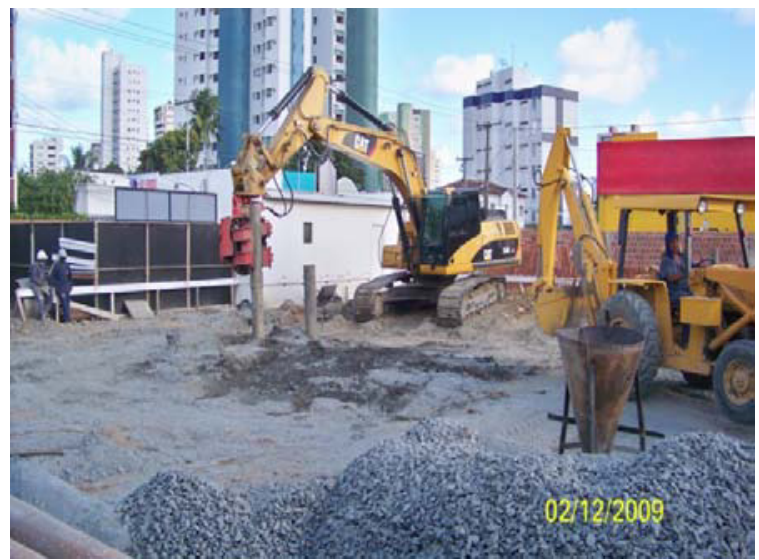

Figure 13 - Surroundings of the construction 4

Figure 14 presents the grid of measurement points of construction 4 where noise levels were collected. Figures 15 and 16 show the spatial distribution and the isolines of the noise, respectively. The biggest amplitude of the noise was measured in point $5(32 \mathrm{~m}$ and $22 \mathrm{~m})$ with a value of $97,7 \mathrm{~dB}$, exactly in the source of emission of noises. The smallest amplitude was measured in point $12(0$ and $17 \mathrm{~m})$ with a value of $70,4 \mathrm{~dB}$.

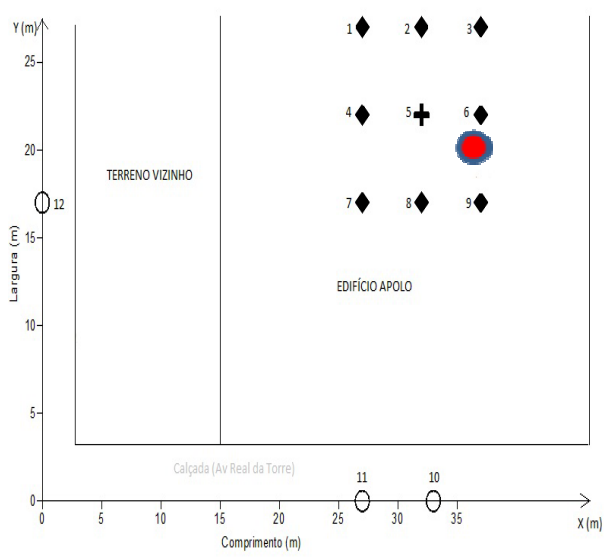

Figure 14 - Grid of measurement points at Construction 4

The noise level was measured at 12 points, the points 10 and 12 are outside the construction site. All the measuresments were above the threshold limits allowed by the city law.
The red point point, represented the source of noise and reached to the highest value measured of $97,7 \mathrm{~dB}$.
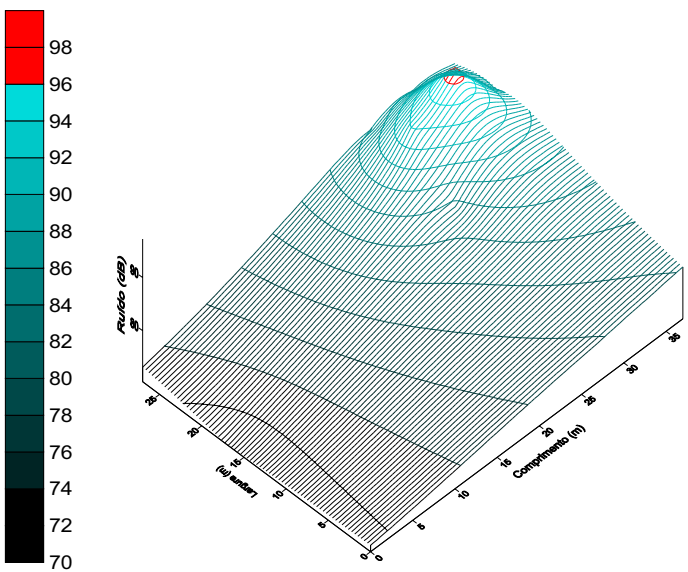

Figure 15 - Spatial Noise Distribution for Construction 4

Figure 16 shows the propagation of the noise, having as origin the emitting source. It is observed that the noise is above the level of tolerance in all the points collected, although when the level noise meter reaches distances above thirty meters the noise is reduced considerably.

A comfort zone is not observed, inside or surrounding the construction site.

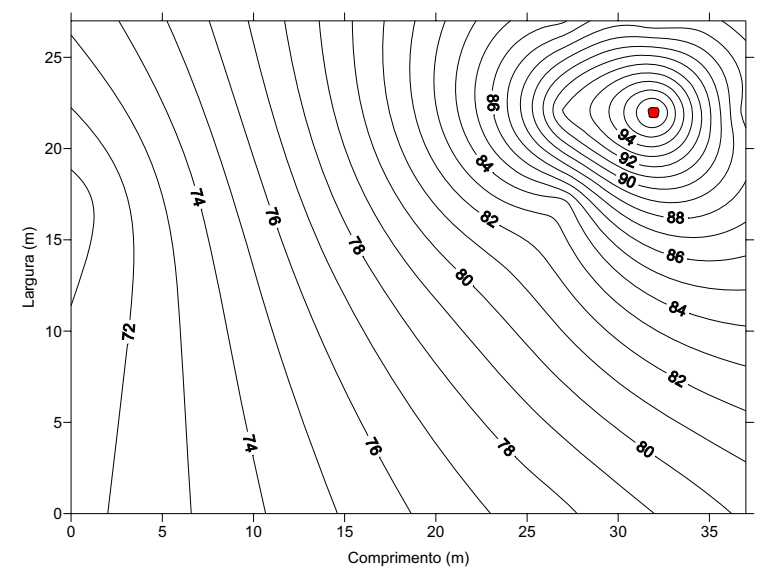

Figure 16 - Noise Isolines for Construction 4

\section{Comparative analysis of the results}

The results showed that the biggest values were obtained at the source of the noise propagation, exactly at the point of execution of the piles, as expected. It is noted that the neighborhood noise of the monitored constructions is highly increased by driving and drilling piles. 
Table 2 presents a summary of the main information collected at the four sites where noise levels were studied at the foundation phase.. Calculations of the background noise and the logarithmic subtraction were made to determine the isolated effect of each analyzed system. It is evident that the noise produced by the pile driving/drilling systems are not affected by the background noise, because they are considerably higher than it is.

The intention of comparing the noise of the four types of piles largely used in the foundations of Recife in the highly urbanized areas, aims to identify which pile method causes the smallest noise effect on the neighborhood. It is noted that the continuous helical displacement pile studied presented the smallest noise increase followed by the Terra Probe vibratory compaction pile, the prefabricated piles. The one with the highest noise impact was the site that used the traditional compaction pile.. These values depend on several conditions, such as: equipment maintenance, time of use and level of technology of the equipment. A more detailed study that includes a higher number of samples should be conducted to verify the correlation among the diverse influencing factors.

The importance of studying the effect, dimension, and propagation of noise was noted during the field study. It was noted that execution of foundations generates unpleasant effects both to the peace of the residential neighborhood and to the workers at the building site, even when they are not working at the activity generating the noise. The noise generated by any activity reach workers in the other activities at the building site.

The study points out for special attention the mechanized processes, such as the ones used in the vibratory compaction pile, where three types of equipment are used: vibrator, hydraulic mechanical shovel and backhoe, as this advanced technology caused a noise a bit bigger that the one emitted by the mechanic pile of the prefabricated stake, according to what is presented in the Table 2.
Table 2

Comparative Analyses among Piles.

\begin{tabular}{|c|c|c|c|c|}
\hline $\begin{array}{c}\text { Type of } \\
\text { foundation. }\end{array}$ & 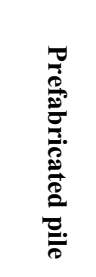 & 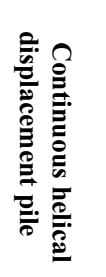 & 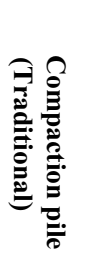 & 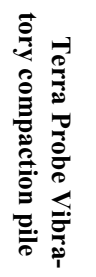 \\
\hline $\begin{array}{l}\text { Neigh- } \\
\text { borhood }\end{array}$ & 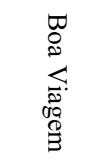 & $\begin{array}{l}\square \\
0 \\
\infty \\
\vdots \\
\vdots \\
\frac{0}{2}\end{array}$ & 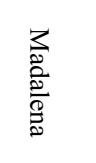 & 훙 \\
\hline $\begin{array}{c}\text { \# of } \\
\text { points } \\
\text { measured. }\end{array}$ & 31 & 13 & 15 & 12 \\
\hline $\begin{array}{l}\text { Background } \\
\text { noise }(\mathrm{dB})\end{array}$ & 49 & 63 & 51 & 70.2 \\
\hline \multirow{2}{*}{$\begin{array}{l}\text { Highest } \\
\text { noise val- } \\
\text { ue(dB) }\end{array}$} & 95.7 & 85.7 & 107 & 97.7 \\
\hline & *95.7 & $* 85.7$ & $* 107$ & $* 97.6$ \\
\hline \multirow{2}{*}{$\begin{array}{l}\text { Lowest } \\
\text { noise value } \\
\text { (dB) }\end{array}$} & 78.1 & 69.4 & 69.2 & 70.4 \\
\hline & $* 78.1$ & *68.3 & *69.1 & *56.9 \\
\hline $\begin{array}{c}\text { Pile } \\
\text { depth }(\mathrm{m})\end{array}$ & 18 & 35 & 6 & 7 \\
\hline
\end{tabular}

*The values represent the noise produced by the piles subtracting logarithmically the background noise

\section{Final Consideration}

Noise measurements were taken at 71 points, distributed across four types of foundations: Concrete prefabricated piles; continuous helical displacement piles; compaction piles to improve traditional soil (pile driver) and compaction piles for improving soil using hydraulic vibrator SP-60 (Terra Probe).

The results showed that in the regions analyzed, at only three points was the noise within the limits allowed by city law, which is $70 \mathrm{~dB}$. However, the areas marked in yellow, so-called zones of comfort, are regions outside the area of the building site and far from the source emitting the noise.

Continuous helical displacement piles generate a lower level of noise compared to the other types of foundations analyzed, providing more comfort to the neighborhood. It was noted that the use of a free fall pile driver causes elevated noises. Comparing the four types of foundation, it was verified that the municipal authorities must conduct a more effective 
inspection of construction sites, as the law is not currently being obeyed.

This work can be considered a pioneering effort with regard to preoccupation with quantifying indicators of noise in the construction of buildings, considering that from October 2009 on, the city of Recife implemented through the Environmental Directorate the obligation of the constructor to formulate, for each worksite, a simplified neighborhood impact report in order to obtain an operational license.

\section{Acknowledgments}

This paper was finished during the post-doctoral work of Emilia Kohlman Rabbani at University of Minho, financed by CAPES Process No. 0770-11-6, who would like to acknowledge the help of Dr. Said Jalali and Dr. Pedro Arezes from the University of Minho Portugal, that have given the researcher means and support for its successful completion and the support of Dr. Aviad Shapira from Technion University, Israel. The results presented were obtained during a Masters student's dissertation from the Civil Engineering Masters Program (PEC) of the Polytechnic School of the University of Pernambuco (POLI/UPE), Adolpho Guido de Araújo, who also received support from the Coordination for Improvement of Higher Education Personnel (CAPES), and help from the State Agency of the
Environment and Hydraulic Resources (CPRH), Laboratório de Tecnologia Ambiental (LABTAM) of ITEP, AMBITEC, NSHT and the Occupational Safety and Health Laboratory (LSHT) of POLI/UPE.

\section{References}

[1] Andrade, S.M.M. (2004) Metodologia para Avaliação de Impacto Ambiental Sonoro da Construção Civil em Meio Ambiente Urbano. Tese de Doutorado. COPPE/UFRJ, Rio de Janeiro, 2004.

[2] Associação Brasileira de Normas Técnicas, NBR 10151: acústica - avaliação do ruído em ares habitadas, visando o confoto da comunidade - procedimento. Rio de Janeiro,2000.

[3] Associação Brasileira de Normas Técnicas, NBR 10152: Níveis de ruído para conforto acústico. Rio de Janeiro,1987.

[4] Alvarenga, B., Máximo, A. Curso de Física. 2. ed. São Paulo: Harbra, 1986, p.605.

[5] Priori Junior, L; Menezes, J.R.R; Guedes, R.; Neto, S.B.F. Construcão Sustentável: Potencialidades e desafios para desenvolvimento sustentável na construção civil. Editora Brascolor, 22a Edição, Recife, 2008, 48p.

[6] Conselho Nacional de Meio Ambiente.Resolução CONAMA No01: 1986. ed.Brasília: IBAMA.

[7] Real, J. C. Unidade de Pesquisas Técnicas. FEDERAÇÃO DA INDUSTRIA DE ESTADO DE PERNAMBUCO, 02 Fev. 2011. Disponível em: http://www.fiepe.org.br.Acesso em: 20 Abr. 2011.

[8] Saliba, T. M. Manual prático de avaliação e controle de Ruído. 3.ed. São Paulo: LTr, 2007, p. 110.

[9] Zannin, P.H.T,; Szeremeta, B. Avaliação da poluição sonora no parque Jardim Botânico de Curitiba, Paraná, Brasil. Caderno de Saúde Pública. (ENESP. Impresso), Brasil, v. 19, n.2, p. 683-686, 2003. 